\title{
Effect of Gadolinium Content on the Corrosion Behavior of Magnesium Alloys in 1 wt.\% NaCl Solution
}

\author{
N. Zidane, ${ }^{a}$ Y. Ait Albrimi, ${ }^{a}$ A. Ait Addi, ${ }^{a}$ R. Ait Akbour, ${ }^{a}$ \\ J. Douch, ${ }^{a}$ A.Nahlé ${ }^{b}$ and M. Hamdani ${ }^{a}{ }^{*}$ \\ ${ }^{a}$ Laboratoire de Chimie Physique, Faculté des Sciences, Université Ibn Zohr, B.P. 8106 \\ CitéDakhla, Agadir, Maroc. \\ ${ }^{b}$ Department of Chemistry, Corrosion Prevention \& Control Research Center, College of Sciences, \\ University of Sharjah, PO Box: 27272, United Arab Emirates.
}

\begin{abstract}
The aim of this work was to study the effect of gadolinium content on the corrosion behavior of magnesium alloys in $1 \mathrm{wt} . \% \mathrm{NaCl}$ solution at $21.5( \pm 0.5){ }^{\circ} \mathrm{C}$. Four $\mathrm{Mg}-\mathrm{Gd}$ alloys, namely Mg-2 wt.\% Gd, Mg-5 wt.\% Gd, Mg-10 wt.\% Gd, and Mg-15 wt.\% Gd, were studied. Weight loss measurements, potentiodynamic tests, electrochemical impedance spectroscopy, XR diffraction, and scanning electron microscopy combined with energy-dispersive X-ray spectroscopy (SEM-EDS) were performed on the four Mg-Gd samples. The results showed the influence of the Gd content on the corrosion behavior of these alloys in $1 \mathrm{wt} \% \mathrm{NaCl}$ solution. The corrosion resistance of the $\mathrm{Mg}-\mathrm{Gd}$ alloys was improved with the introduction of $10 \mathrm{wt} . \% \mathrm{Gd}$ in $\mathrm{Mg}$ matrix. Thus, weight loss and electrochemical measurements revealed the better corrosion resistance for $\mathrm{Mg}$ 10 wt. \% Gd alloy. Further addition of Gd exceeding $10 \mathrm{wt} \%$ in a magnesium matrix reduces the corrosion resistance of $\mathrm{Mg}$-alloy and induces an incremental increase in the corrosion rate.
\end{abstract}

Keywords: magnesium alloys, biomaterials, corrosion resistance, gadolinium alloying.

\section{Introduction}

Properties of high strength-to-weight ratio and high stiffness-to-weight ratio make magnesium based alloys very attractive for uses where lightweight materials are required [1-6]. However, due to their biocompatibility, magnesium alloys are suitable candidate for degradable material as implants. Moreover, these

\footnotetext{
* Corresponding author. E-mail address: hamdani.mohamed@gmail.com
} 
materials have received considerable attention due to the fact that their mechanical characteristics are close to those of natural bone [7-10]. The main limitation of magnesium for use as an implant is its very high corrosion rate, especially in wet or aqueous environments. The corrosion of $\mathrm{Mg}$ is accompanied by hydrogen evolution and basification of the electrolytic solution. One of the most efficient ways to protect $\mathrm{Mg}$ from corrosion is by alloying it with different metals. Therefore, efforts have been made to improve its corrosion performance by modifying the composition with one or more elements in various weight percentages. Thus, alloying is commonly used to protect $\mathrm{Mg}$ against corrosion phenomena that rely greatly on their microstructure and the distribution of alloying elements in the $\mathrm{Mg}$ matrix [11-15). In order to improve the corrosion resistance of such $\mathrm{Mg}$ alloys, this present research was carried out. Magnesium alloys containing particularly high solubility rare earth metals (RE) such Gd, Dy, $\mathrm{Y}, \mathrm{Nd}, \mathrm{La}$, and Ce [11-21] have recently been studied. The distribution of these alloying elements in the $\mathrm{Mg}$ matrix was responsible for the change of the corrosion behavior of $\mathrm{Mg}$ alloys by the formation of new a corrosion resistant crystallographic $\beta$-phase [22-24]. Even though the corrosion resistance of some magnesium alloys can be enhanced by adding elements, the latter should have low toxicity for biomedical applications. Recent references suggest that $\mathrm{Mg}-\mathrm{Gd}$ alloy is suitable for a biocompatible implant as Gd has high solubility in solid $\mathrm{Mg}$ [7]. As yet, literature reports are relatively scarce [7,25]. However, investigation of the influence of the amount of $\mathrm{Gd}$ in binary $\mathrm{Mg}-\mathrm{Gd}$ alloys on the corrosion behavior in $1 \mathrm{wt} . \% \mathrm{NaCl}$ solution has shown that introducing $\mathrm{Gd}$ in optimum concentration led to a reduction of the corrosion rate as long as the Gd was in solid solution. The corrosion rate increased significantly as soon as there were precipitates in the microstructure of the $\mathrm{Mg}-\mathrm{Gd}$ alloys [7]. However, some recent studies on $\mathrm{Mg}-\mathrm{Y}$ and $\mathrm{Mg}-\mathrm{Gd}$ alloys prepared by magnetron sputtering reported that there was no significant change in the corrosion rate with alloying content in 3.5 wt. $\% \mathrm{NaCl}$ solution saturated with $\mathrm{Mg}(\mathrm{OH})_{2}$ [25]. It was reported that the investigation was carried out on Mg-alloys using long-term techniques such as weight loss determinations and hydrogen measurements, or short term techniques such as potentiodynamic measurements, electrochemical impedance spectroscopy, and surface characterization (SEM-EDS, XRD, and XPS). In general, good corrosion resistance of a given material can be identified by low corrosion current density, high corrosion potential and high polarization resistance.

The aqueous $\mathrm{Mg}$ corrosion process and hydrogen evolution can be represented by the reactions $[8,26]$ :

$$
\begin{aligned}
& \mathrm{Mg} \quad \rightarrow \mathrm{Mg}^{2+}+2 \mathrm{e}^{-} \quad \text { (anodic reaction) (1) } \\
& 2 \mathrm{H}_{2} \mathrm{O}+2 \mathrm{e}^{-} \rightarrow 2 \mathrm{OH}^{-}+\mathrm{H}_{2} \quad \text { (cathodic reaction) (2) }
\end{aligned}
$$

The overall corrosion reaction leads to the formation of $\mathrm{Mg}(\mathrm{OH})_{2}$ accompanied by the hydrogen evolution, following Equation 3:

$$
\mathrm{Mg}+2 \mathrm{H}_{2} \mathrm{O} \rightarrow \mathrm{Mg}(\mathrm{OH})_{2}+\mathrm{H}_{2}
$$


In the presence of chloride ions, $\mathrm{Mg}^{2+}$ ions react to form the soluble salt $\mathrm{MgCl}_{2}$, according to Equation 4:

$$
\mathrm{Mg}^{2+}+2 \mathrm{Cl}^{-} \rightarrow \mathrm{Mg}(\mathrm{Cl})_{2}
$$

It is well known that the corrosion resistance of $\mathrm{Mg}$-alloys decreases as the concentration of $\mathrm{Cl}^{-}$increases in the aqueous solution, due to the destruction of the protective layer on their surface. Also, the corrosion resistance of such materials is mainly improved in strong rather than in weak-alkaline solution, or neutral or acidic solutions [27]. This is likely due to the formation of a compacted corrosion product layer on the surface of the alloy in alkaline solutions, which also occurs with a decrease in the concentration of aggressive ions. It was concluded that the corrosion protection products layer was better at high $\mathrm{pH}$ values of the solution. The stability of protective layer decreased with either increasing $\mathrm{Cl}^{-}$concentration or lowering of the solution $\mathrm{pH}$ [27].

In the present study, binary $\mathrm{Mg}-\mathrm{Gd}$ alloys were investigated to determine the influence of different amounts of $\mathrm{Gd}$ on the corrosion behavior of magnesium alloys. Four different Mg-Gd alloys (2, 5, 10, and 15 wt.\%) were tested electrochemically in $1 \mathrm{wt} . \% \mathrm{NaCl}$ solution at $21.5^{\circ} \mathrm{C}$. Weight loss, open circuit potential, Tafel polarization curves, electrochemical impedance spectroscopy (EIS), scanning electron microscopy combined with energy-dispersive X-ray spectroscopy (SEM- EDS), and XR diffraction were used. The main objectives of the present study were (i) to investigate the effect of Gd content on the corrosion behavior of Mg-Gd alloys, and (ii) to answer the question "can alloying improve and tailor the corrosion resistance of the $\mathrm{Mg}-\mathrm{Gd}$, or not?".

\section{Experimental}

\section{Materials and samples}

For the present investigation, $\mathrm{Mg}-2$ wt.\% Gd, Mg-5 wt.\% Gd, Mg-10 wt.\% Gd, and Mg-15 wt.\% Gd were used. These materials were offered by a German team that has already described the preparation method of the $\mathrm{Mg}$ alloys in a previous publication [7]. All investigated materials were cylindrical in shape $(15 \mathrm{~mm}$ in diameter and $4 \mathrm{~mm}$ thickness) cut into $\mathrm{Mg}$-alloy rods. The samples were prepared by grinding each side with 1200 grid emery paper, the surfaces degreased ultrasonically with ethanol and finally dried in open air prior to corrosion testing. 1 wt.\% (10 g.. $\left.{ }^{-1}\right)$ sodium chloride aqueous solution was prepared using bi-distilled water. The initial $\mathrm{pH}$ value of the prepared solution was $6.5( \pm 0.1)$ and the temperature was kept at $21.5( \pm 0.5){ }^{\circ} \mathrm{C}$ using a DBOmeter chamber. The $\mathrm{pH}$ was measured using a pH-meter (Knick 766 Calimatic). All reagents used in this work were analytical grade.

\section{Weight loss measurements}

After cleaning, samples of each alloy type were immersed (i.e., suspended) in $200 \mathrm{~mL}$ of naturally aerated quiescent $1 \mathrm{wt} . \% \mathrm{NaCl}$ solution at $21.5( \pm 0.5){ }^{\circ} \mathrm{C}$. The samples were weighed before and after immersion in the unstirred solutions, 
which were open to the atmosphere. After exposure, corrosion products were removed by immersing the samples in 180 g.L.-1 chromic acid for 20 minutes at room temperature [7]. After acid cleaning, samples were rinsed ultrasonically in ethanol, dried in the open air then reweighed. The difference in mass of the $\mathrm{Mg}$ alloy samples per surface unit area is defined as the corrosion rate $(\mathrm{CR}=\Delta \mathrm{m} / \mathrm{S})$ in the solution after 24 hours of immersion. Each measurement was performed twice on a new specimen and the average was reported. The standard deviation of the observed weight loss was less than 6\%. After 24 hours of immersion and before acid cleaning, all specimens increased in weight. An analytical balance with an accuracy of $\pm 0.1 \mathrm{mg}$ was used for weighing the Mg-alloy specimens. The average corrosion resistance of the alloys was also calculated and expressed in mm.year ${ }^{-1}$ according to the following equation (7):

$$
C R=\frac{8.76 \times 10^{4}}{A \times t \times \rho} \Delta m
$$

where: $\Delta \mathrm{m}=$ weight change $[\mathrm{g}] ; \mathrm{A}=$ surface area $\left[\mathrm{cm}^{2}\right] ; \mathrm{t}=$ time $[$ hour $]$, and $\rho=$ density of the alloy $\left[\mathrm{g} . \mathrm{cm}^{-3}\right]$.

\section{Electrochemical measurements}

$\mathrm{Mg}$-alloy samples in disc form were used as the working electrodes in quiescent 1 wt. $\% \mathrm{NaCl}$ aqueous solution at $21.5( \pm 0.5){ }^{\circ} \mathrm{C}$. The specimens were mounted on a glass tube using Araldite epoxy resin and only one side of the specimen was in contact with the electrolyte $\left(1.8 \mathrm{~cm}^{2}\right)$. The electrical contact with the remaining side of the test electrode was made using a rigid copper wire.

Electrochemical studies were carried out in a single-compartment three-electrode glass cell. The potential of the working electrode was measured against a saturated calomel electrode (SCE) $(0.240 \mathrm{~V}$ vs. SHE). The SCE was connected through a $\mathrm{KCl}$-containing agar-agar salt bridge, the tip of which was placed as close as possible to the surface of the working electrode in order to minimize the solution resistance between the test and reference electrodes (IR drop). The aerated and unstirred electrolyte had a volume of $200 \mathrm{~mL}$. The counter electrode consisted of a platinum plate, $6 \mathrm{~cm}^{2}$ in surface area. The volume of the aerated and unstirred electrolyte used was $200 \mathrm{~mL}$.

The electrochemical study was performed using a computerized electrochemical potentiostat set Voltalab PRZ 100 (Radiometer-Analytical). The corrosion behavior of the Mg-alloys was investigated using potentiodynamic polarization technique. The polarization curves were measured after determination of the open circuit potential of the test electrode. For all electrochemical investigations, the open-circuit potential (OCP) was measured for at least 90 minutes. The polarization curves were recorded in the range of -2.0 to $+1.0 \mathrm{~V}$ vs. SCE in 1 wt.\% $\mathrm{NaCl}$ aqueous solutions at a scan rate of $1 \mathrm{mV} \cdot \mathrm{s}^{-1}$ while each specimen was held in the vertical position.

The experimental procedures and conditions employed in the EIS study were similar to those described previously [28,29]. An AC voltage amplitude of $5 \mathrm{mV}$ peak-to-peak voltage excitation and a frequency range of $10^{-2}-10^{5} \mathrm{~Hz}$ were 
employed during the impedance measurements. Results were displayed in the form of Nyquist plots. Each experiment was repeated at least three times to ensure reproducibility.

\section{SEM- EDS and X-ray diffraction}

The corrosion morphologies of the Mg-alloys were characterized using a high resolution SEM (Zeiss Ultraplus 40, Germany) equipped with an energy dispersive X-ray spectrometer (EDS) to analyze the composition of the samples. The phase content of the samples was monitored using X-ray diffraction (XRD) (Pan Analytical X'Pert PRO, CuK $\alpha=1.5406 \AA$ A) from Kiel University, Germany.

\section{Results}

\section{pH measurements}

The corrosion of the $\mathrm{Mg}$-alloys immersed in $1 \mathrm{wt} . \% \mathrm{NaCl}$ aqueous solution was accompanied by hydrogen evolution, according to the overall reaction (equation 3 ), leading to an increase of the alkalinity of the solution. Fig. 1 depicts typical hydrogen evolution through the $\mathrm{pH}$ change as a function of immersion time of a specimen $\mathrm{Mg}$-alloy in $200 \mathrm{~mL}$ of $1 \mathrm{wt} . \% \mathrm{NaCl}$ solution at $21.5^{\circ} \mathrm{C}$. The solution was homogenized prior to the $\mathrm{pH}$ measurements. The $\mathrm{pH}$ values of the solution increased rapidly from 6.5 to 9.3 during the first 15 minutes. This was followed by a period of slower $\mathrm{pH}$ increase between 9.3 and 10.0 during the next 30 minutes.

After 90 minutes, the $\mathrm{pH}$ of the solution reached the steady state (10.5). The $\mathrm{pH}$ of the used solutions did not exceed 10.7 irrespective of the composition of the samples and the immersion time. This result probably was due to $\mathrm{Mg}(\mathrm{OH})_{2}$ that was suspended in water (called milk of magnesia) which exhibits a $\mathrm{pH}$ between 9.5 and 10.5. The formation of one $\mathrm{Mg}(\mathrm{OH})_{2}$ molecule leads to formation of one $\mathrm{H}_{2}$ molecule (equation 3).

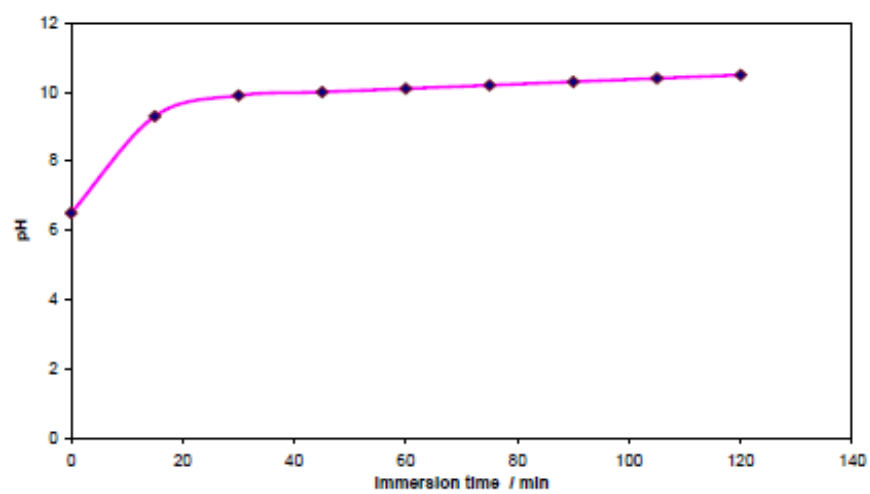

Figure 1. $\mathrm{pH}$ measurements during time of immersion of $\mathrm{Mg}$-alloys in $1 \mathrm{wt} . \% \mathrm{NaCl}$ solution at $21.5^{\circ} \mathrm{C}$.

Doepke et al.[30] reported that the rising $\mathrm{pH}$ during immersion of $\mathrm{Mg}$ in $\mathrm{NaCl}$ solutions was most likely moderated by the formation of a corrosion product laying on the surface of the $\mathrm{Mg}$ sample that decreased the overall corrosion rate. In addition, the increased $\mathrm{pH}$ of the solution decelerated the corrosion activity 
due to the precipitation of a passivating film on the surface [31]. Generally, the magnesium alloy has high corrosion resistance in alkali solution but is active in acidic or neutral environments [27,32]. In strong alkaline solution, much of the $\mathrm{Cl}^{-}$ions were replaced by $\mathrm{OH}^{-}$ions so that the adsorption of $\mathrm{Cl}^{-}$on the layer was consequently reduced.

\section{Weight loss measurements}

Weight loss determinations for the four $\mathrm{Mg}$-alloys have been performed after immersion in $1 \mathrm{wt} . \% \mathrm{NaCl}$ solution after 24 hours at $21.5^{\circ} \mathrm{C}$, and the results are depicted in Fig. 2. The weight of the corrosion products that remained insoluble on the Mg-alloy surface was determined by weighing the corroded sample before and after cleaning. It was observed that the corrosion products that formed during immersion in the $\mathrm{NaCl}$ solution remained largely insoluble on the surface of the samples. Table 1 summarizes the corrosion rates obtained for the different $\mathrm{Mg}$ alloys. It can be observed from the data that the value of corrosion rate (CR) decreased and reached $2.6 \mathrm{mg} \cdot \mathrm{cm}^{-2}$. day ${ }^{-1}$ which corresponds to $4.0 \mathrm{~mm}$.year ${ }^{-1}$, when the percentage of $\mathrm{Gd}$ increased to $10 \mathrm{wt} . \%$. However, the corrosion rate was the highest $\left(16.6 \mathrm{mg} \cdot \mathrm{cm}^{-2} \cdot \mathrm{day}^{-1}\right)$ for the alloy containing $15 \mathrm{wt} . \% \mathrm{Gd}$. In addition, the color of the solution used with the 15 wt.\% Gd sample turned whitish, which could be clearly observed with the naked eye during the immersion test period. This milk-like coloration could be due to the presence of great quantity of $\mathrm{Mg}(\mathrm{OH})_{2}$, i.e., milk of magnesia, in colloidal form in the solution.

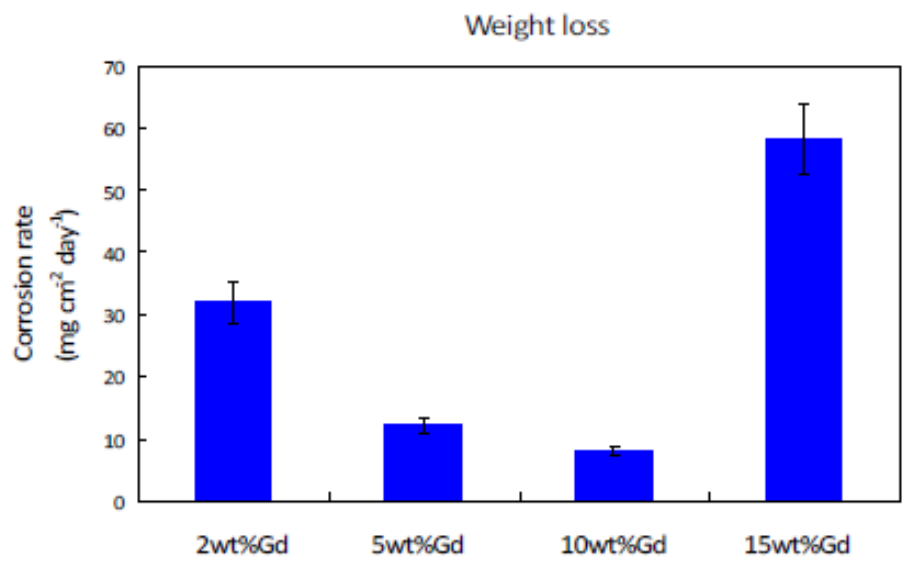

Figure 2. Weight loss of $\mathrm{Mg}$-alloys $\left(\mathrm{mg} . \mathrm{cm}^{-2}\right)$ in $1 \mathrm{wt} . \% \mathrm{NaCl}$ solutions during 24 hours at $21.5^{\circ} \mathrm{C}$.

Table 1.Corrosion rates of $\mathrm{Mg}$-alloys in $1 \mathrm{wt} . \% \mathrm{NaCl}$ solution after 24 hours immersion at $21.5^{\circ} \mathrm{C}$.

\begin{tabular}{|c|c|c|c|}
\hline \multirow{2}{*}{ Mg-alloys } & \multirow{2}{*}{$\begin{array}{l}\text { Density of the alloy* } \\
\qquad\left({\left.\mathrm{g} . \mathrm{cm}^{-3}\right)}^{-3}\right.\end{array}$} & \multicolumn{2}{|c|}{ Corrosion rate $(\mathrm{CR})$} \\
\hline & & $\left(\mathrm{mg} . \mathrm{cm}^{-2} \cdot\right.$ day $\left.^{-1}\right)$ & $\left(\mathrm{mm} . \mathrm{year}^{-1}\right)$ \\
\hline Mg-2wt $\%$ Gd & 1.86 & 9.1 & 17.9 \\
\hline $\mathrm{Mg}-5 \mathrm{wt} \% \mathrm{Gd}$ & 2.05 & 3.2 & 5.7 \\
\hline $\mathrm{Mg}-10 \mathrm{wt} \% \mathrm{Gd}$ & 2.35 & 2.6 & 4.0 \\
\hline $\mathrm{Mg}-15 \mathrm{wt} \% \mathrm{Gd}$ & 2.66 & 16.6 & 22.8 \\
\hline
\end{tabular}

*The density of different alloys is computed to determine corrosion rates (mm.year ${ }^{-1}$ ) (Equation 5). 
For the same binary Mg-Gd alloy and under the same conditions, Hort et al. [7] reported from weight loss measurements that the corrosion rate initially decreased and then increased. Mg-10 wt.\% Gd alloy exhibited the lowest corrosion rate. A similar trend was also reported with the binary $\mathrm{Mg}-10 \mathrm{wt} . \%$ Dy alloy [17], and the mechanism responsible for an optimal corrosion resistance for $\mathrm{Mg}-10$ wt.\% RE (rare earth metals) is under investigation. The corrosion process of $\mathrm{Mg}$-alloys when immersed in $\mathrm{NaCl}$ solution could be explained on the basis that the surface of the alloy is covered with a film of corrosion products. In some part of the alloys surface, the film is permeable, which may permit the $\mathrm{Cl}^{-}$ions to penetrate and reach active sites on the surface of the alloy beneath the formed corrosion product film. $\mathrm{Cl}^{-}$ions may also dissolve $\mathrm{Mg}(\mathrm{OH})_{2}$ which in turn will thin the passive film, allowing the aggressive ions to reach the alloy substrate more easily.

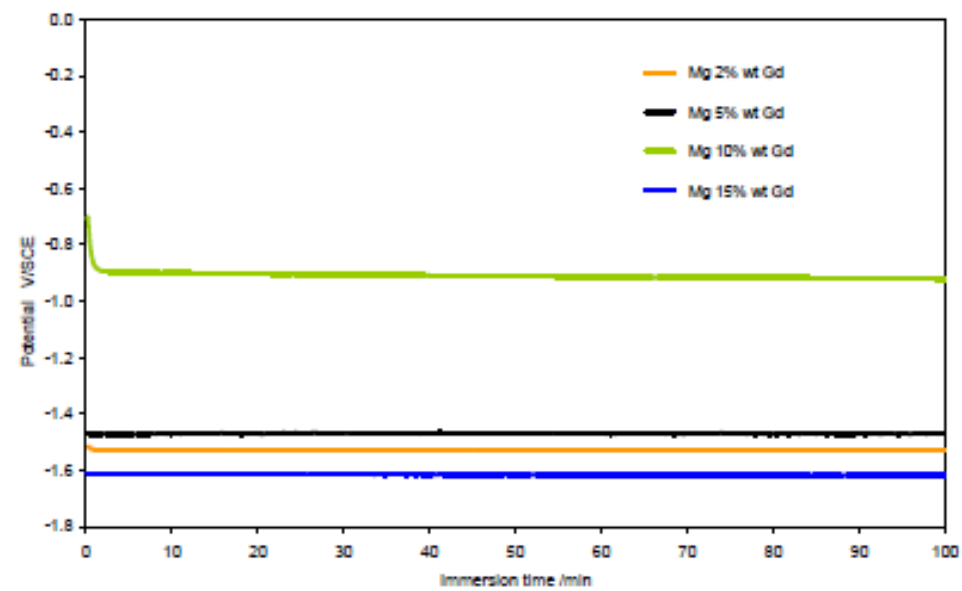

Figure 3. Evolution of the open-circuit potential versus timefor $\mathrm{Mg}$-alloy electrodes in 1 wt.\% $\mathrm{NaCl}$ solution at $21.5^{\circ} \mathrm{C}$.

\section{Open circuit potential}

Fig. 3 shows the open circuit potential (OCP) of the Mg-alloy electrodes versus time in aerated and unstirred 1 wt. $\% \mathrm{NaCl}$ solutions at $21.5{ }^{\circ} \mathrm{C}$. The curves demonstrate that most of the $\mathrm{Mg}$-alloy electrodes reached a steady from the beginning, except in the case of the Mg-10 wt.\% Gd alloy. The OCP values of the Mg-alloys changed in the following increasing order: Mg-15 wt.\% Gd $<\mathrm{Mg}$ 2 wt.\% Gd $<\mathrm{Mg}-5$ wt.\% Gd $<\mathrm{Mg}-10 \mathrm{wt} \% \mathrm{Gd}$. At the onset of corrosion there was an incubation period, during which the OCP of Mg-10 wt.\% Gd tends initially to decrease abruptly towards the negative direction (during the first minute), indicating that a film has been formed on the surface of the specimen, before reaching a steady state at $-0.888 \mathrm{~V}$ vs. SCE. The steady state condition indicates that a dynamic balance has been established between development of the corrosion activity and the deposit of the corrosion products on the surface of the alloy when the whole specimen surface has corroded. The time needed to attain a steady state was about 3-4 minutes. For all Mg-alloys, the OCP remained constant up to 100 minutes. The steady state condition might be due to the lack of variation in the interface composition. By comparing the OCP values obtained for all the specimens it can be observed that the OCP value of Mg-10 wt.\% Gd shifted to a noble potential value by at least $0.6 \mathrm{~V}$. This increase of OCP suggests 
a reduction of susceptibility of the alloy to the corrosion process but the OCP values do not provide any information on the corrosion kinetics [33]. That is to say that the $\mathrm{Mg}$-alloy interfaces immersed in $1 \mathrm{wt} . \% \mathrm{NaCl}$ solution probably undergo formation of a magnesium hydroxide film wherein the adsorbed $\mathrm{Cl}^{-}$ions do not reduce the effectiveness of the protective film.

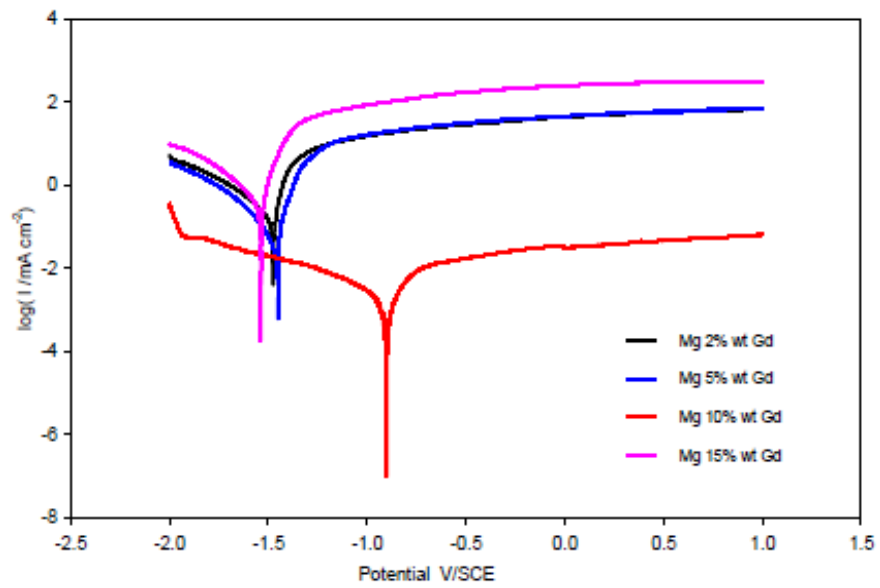

Figure 4. Polarization curves of different Mg-alloy electrodes in 1 wt. $\% \mathrm{NaCl}$ solution, scan rate $1 \mathrm{mV} . \mathrm{s}^{-1}$ at $21.5^{\circ} \mathrm{C}$.

\section{Tafel polarization measurements}

Potentiodynamic polarization measurement is a convenient and effective method to characterize the thermodynamics and the kinetics of the reaction which takes place on the working electrode surface. The corrosion potential ( $\left.E_{\text {corr }}\right)$ and corrosion current $\left(\mathrm{I}_{\mathrm{corr}}\right)$ values can be extracted from the potentiodynamic polarization curves. Fig. 4 shows Tafel current-potential curves for the Mg-alloys after 90 minutes of immersion in aerated stagnant $1 \mathrm{wt} . \% \mathrm{NaCl}$ solutions at 21.5 ${ }^{\circ} \mathrm{C}$. The polarization curves are not symmetrical on the anodic and cathodic branches. The curves are recorded over the potential range of -2.0 to $+1.0 \mathrm{~V}$ vs. SCE and scanning in the positive direction at a scan rate of $1 \mathrm{mV} \cdot \mathrm{s}^{-1}$. All of the polarization curves showed the same trend. The cathodic polarization curves are assumed to represent the hydrogen evolution through reduction of the water molecules and followed Tafel behavior, while the anodic polarization curves represent the dissolution of magnesium. The polarization curves obtained were similar to each other in terms of current densities and corrosion potential, with the exception of the polarization curve obtained for the $\mathrm{Mg}-10 \mathrm{wt} \% \mathrm{Gd}$ electrode. Thus, the electrochemical behavior of the three $\mathrm{Mg}$-alloys was similar. The potentiodynamic polarization curve obtained for the $\mathrm{Mg}-10 \mathrm{wt} \% \mathrm{Gd}$ electrode clearly shows that both the cathodic and anodic current densities were

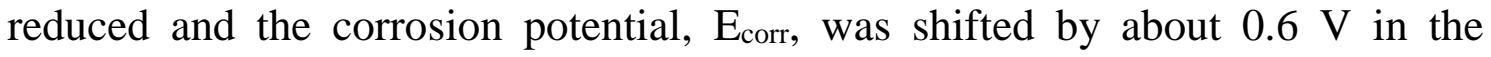
positive direction (less active region). The influence of the $\mathrm{Gd}$ content on the free corrosion potential was negligible for the other three $\mathrm{Mg}$-alloys. The ennoblement of corrosion potential by about $0.6 \mathrm{~V}$ should indicate good corrosion resistance for the $\mathrm{Mg}-10 \mathrm{wt} . \% \mathrm{Gd}$ alloy. This result was consistent with weight loss and OCP measurements. 
Table 2. Electrochemical parameters (OCP, $\mathrm{E}_{\text {corr }}, \mathrm{I}_{\text {corr }}$, and Rct) for Mg-alloy electrodes immersed in $1 \mathrm{wt} . \% \mathrm{NaCl}$ solution at $21.5^{\circ} \mathrm{C}$.

\begin{tabular}{|c|c|c|c|c|c|}
\hline Mg alloys & $\begin{array}{c}\text { Voc } \\
\text { (V vs. SCE) }\end{array}$ & $\begin{array}{c}\text { Ecorr } \\
\text { (V vs. SCE) }\end{array}$ & $\begin{array}{c}\mathbf{I}_{\mathbf{c o r r}} \\
\left(\mathbf{m A . c m}^{-2}\right)\end{array}$ & $\begin{array}{c}-\boldsymbol{\beta}_{\mathbf{c}} \\
(\mathbf{m V})\end{array}$ & $\begin{array}{c}\mathbf{R}_{\mathbf{t c}} \\
\left(\mathbf{\Omega . c m}^{\mathbf{2}}\right)\end{array}$ \\
\hline $\mathrm{Mg}-2 \%$ wt Gd & -1.586 & -1.472 & 0.497 & 210 & 213 \\
\hline $\mathrm{Mg}-5 \%$ wt Gd & -1.463 & -1.452 & 0.223 & 195 & 253 \\
\hline $\mathrm{Mg}-10 \%$ wt Gd & -0.888 & -0.933 & 0.090 & 242 & 325 \\
\hline $\mathrm{Mg}-15 \%$ wt Gd & -1.640 & -1.669 & 4.133 & 132 & 208 \\
\hline
\end{tabular}

The cathodic curves indicated that the cathodic process was not diffusion controlled. During the cathodic process, hydrogen was produced in the form of bubbles on the electrode surface. Therefore the slope of the cathodic curves was steep.

Despite having the same shape, it can be seen that both the anodic part and cathodic part obtained for $\mathrm{Mg}-10 \mathrm{wt} \% \mathrm{Gd}$ electrode presented low current density values compared to the other alloy electrodes. This means that the Mg-10 wt.\% Gd content had significant effects on retarding the cathodic hydrogen evolution reaction and on the dissolution of $\mathrm{Mg}$-alloy. The electrochemical parameters obtained from the polarization curves, including the open circuit potential $(\mathrm{OCP})$, corrosion potential $\left(\mathrm{E}_{\mathrm{corr}}\right)$, and corrosion current densities $\left(\mathrm{I}_{\mathrm{corr}}\right)$, are summarized in Table 2. The values of corrosion current were estimated based on the Tafel extrapolation method for the most linear part of the cathodic branch of the polarization curve back to $E_{\text {corr, }}$, and are given as a function of the nature of the alloy. It is clearly shown that for the $10 \% \mathrm{Gd}$ electrode, the open circuit potential (OCP) was the highest and the corrosion current density was the lowest. Judging from the polarization curves (Fig. 4 and Table 2), the cathodic reaction and the anodic reaction were significantly lower as a result of the addition of 10 wt.\% Gd.

It is evident that the corrosion potential $\left(E_{\text {corr }}\right)$ values are slightly different from those of open circuit potential (OCP) due to the modification into the Mg-alloy electrode surface.

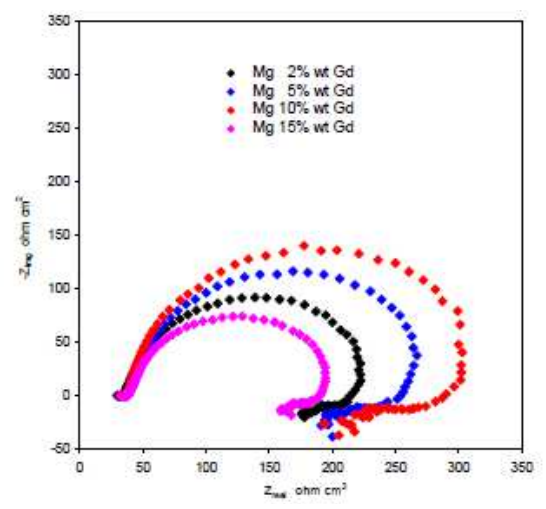

Figure 5. Nyquist diagrams of different $\mathrm{Mg}$-alloy electrodes in $1 \mathrm{wt} . \% \mathrm{NaCl}$ solution.

\section{EIS study}

EIS measurements were performed to characterize the magnesium alloy/solution interface. In order to investigate the corrosion behavior of the alloys and stability of the film formed on the interface, the EIS measurements were carried out at the OCP in 1 wt.\% $\mathrm{NaCl}$ solution. Fig. 5 depicts typical Nyquist plots for the studied 
Mg-alloys. It can be seen from this figure that all of impedance spectra were rather similar, except the difference in the semicircle diameter. The EIS diagram presents the 'semicircles' for capacitive behavior at high frequencies (HF) in combination with an inductive loop at low (LF) frequencies. The impedance response of the electrode, which was apparent from the higher impedance values obtained, changed with the Gd content.

Many studies support the use the capacitive loop to extract the charge transfer resistance Rct to obtain information on the corrosion rate [34-37].The diameter of the capacitive loop is associated with the charge transfer resistance of the corrosion process [35-37]. Rct is inversely related to the corrosion current density. The literature associates the corrosion of magnesium alloys to the diameter of this capacitive loop in the higher frequency region with the charge transfer resistance (Rct) of the corrosion process [38]. Thus, Rct increases in the following order: Mg-15 wt.\% Gd $<$ Mg-2 wt.\% Gd $<\mathrm{Mg}-5$ wt.\% Gd $<\mathrm{Mg}-10$ wt.\% $\mathrm{Gd}$, which ranked the corrosion resistance of alloys in the same way as shown in Table 2. The decrease of Rct means that the corrosion of Mg-alloys accelerates. These results also were consistent with the results obtained by weight loss, OCP and potentiodynamic measurements.

The second loop is present with all the specimens in low magnitude. King et al. [39] studied the corrosion of Mg using EIS and asserted that the electrochemical response usually displays inductive behavior with decreasing frequency. The inductive loop interpretation has been discussed in the literature and was attributed to species adsorption [40,41]. Thus, the inductive loop was ascribed to a process involving $\mathrm{Mg}^{+}$even though there was no firm evidence for the presence of the $\mathrm{Mg}^{+}$ion $[42,43]$, or as $\mathrm{Mg}^{2+}$ ions, or $\mathrm{MgOH}^{+}$, and to the dissolution of the protective film on the electrode surface [38]. For others, the interpretation of the inductive behavior observed in the Nyquist plot is immaterial in studies of electrochemical corrosion as the kinetic information is estimated from the capacitive arc $[38,44]$.

\section{SEM and EDS}

The morphology and the composition of corrosion products formed on $\mathrm{Mg}$-alloys after the 4 hour immersion test in $1 \mathrm{wt} . \% \mathrm{NaCl}$ was characterized by means of scanning electron microscopy equipped with energy-dispersive X-ray spectroscopy (SEM-EDS). Fig. 6 (1 to 4), show the SEM microstructures of the $\mathrm{Mg}$-alloy surfaces after 4 hours immersion in $1 \mathrm{wt} . \% \mathrm{NaCl}$ at $21.5^{\circ} \mathrm{C}$. In general, the film of products was fragile and uncompact. The film formed on the Mg-alloy surface with 2 and $5 \mathrm{wt} . \% \mathrm{Gd}$ showed a cauliflower-like porous shape at a low magnification. At relatively high magnification the deposits were gypsum flower-like. The corrosion compounds formed on the surface of these two alloys contained crevices. The surface obtained after the immersion test of the specimen with $10 \mathrm{wt} . \% \mathrm{Gd}$ was less rough than the former and appeared to be covered by an accretion. The formed film appeared thicker and smoother than on the other alloys, and should protect the Mg metal. The insoluble corrosion products on the surface of the alloy slow down the corrosion rate. The corrosion products formed 
on the 15 wt.\% Gd were smoother but crackled. Even though the layer was thick, it did not offer strong protection.

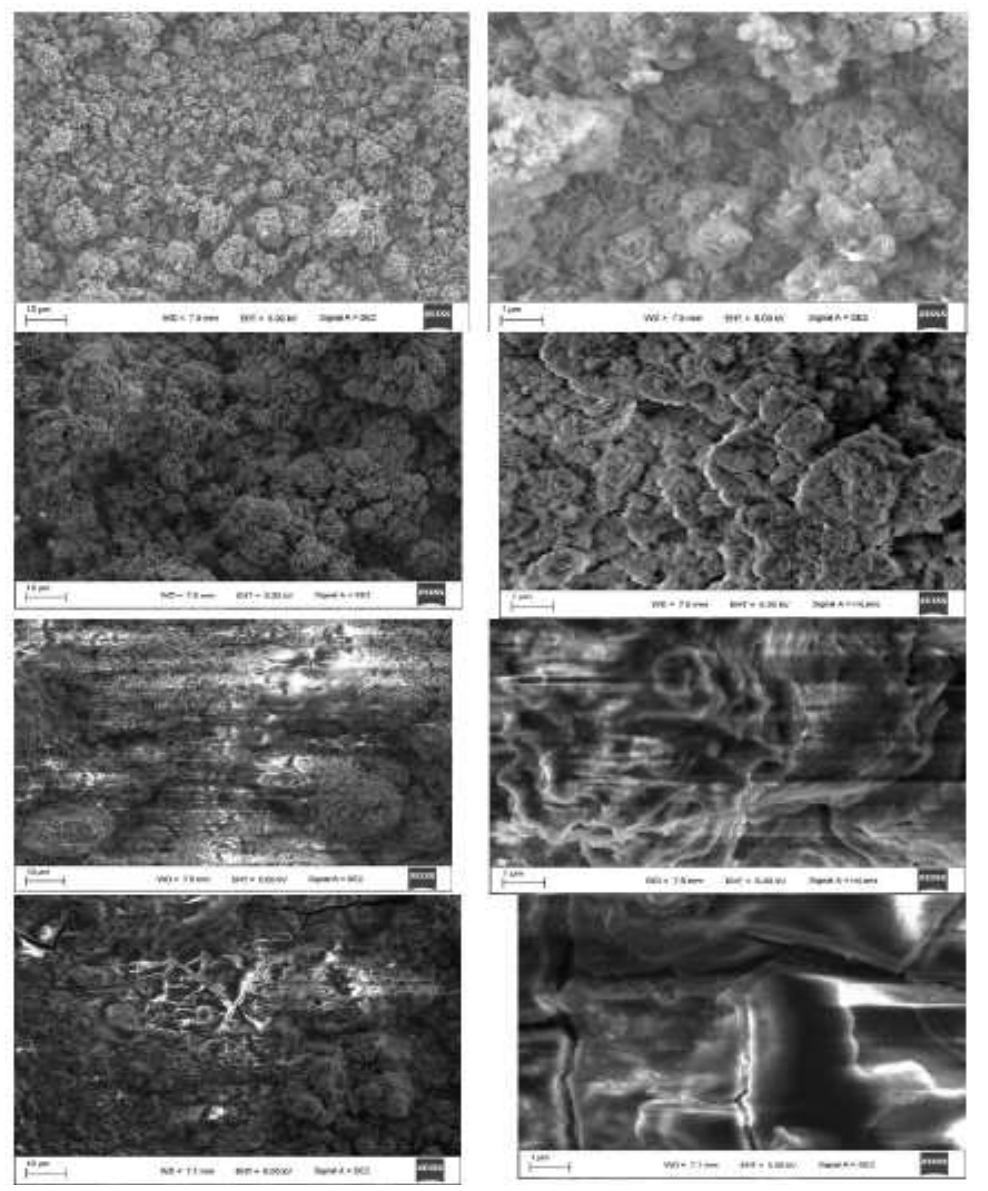

Figure 6. SEM of Mg-alloys after 4 hours immersion in 1 wt. $\% \mathrm{NaCl}$ at $21.5^{\circ} \mathrm{C}$. (1) Mg-2 wt.\% Gd, (2) Mg-5 wt.\% Gd, (3) Mg-10 wt.\% Gd, and (4) Mg-15 wt.\% Gd.

The differences may be caused by the different distribution of alloying elements in microscopic scale and the microstructure of alloys, which are the fundamental reasons for the metal corrosion morphology and corrosion resistance. In order to identify the elemental composition of the corrosion products of different specimens, EDS analysis was performed on the corrosion products from the alloys after 4 hours immersion in $1 \mathrm{wt} . \% \mathrm{NaCl}$ and the results are listed in Table 3. It can be seen that the formed corrosion film on $10 \% \mathrm{Gd}$ alloy contained the highest amount of $\mathrm{Gd}$ and surprisingly the highest amount of $\mathrm{Na}^{+}$and $\mathrm{Cl}^{-}$ions, in addition to a small amount of La.

Table 3. Atomic percentages of elements of different $\mathrm{Mg}$-alloys in 1 wt.\% $\mathrm{NaCl}$ solution after 4 hours of immersion at $21.5^{\circ} \mathrm{C}$.

\begin{tabular}{|c|c|c|c|c|c|c|c|}
\hline Mg-alloys & C & O & Na & Mg & Cl & Gd & La \\
\hline Mg-2\%wt Gd & 3.69 & 66.66 & 0.19 & 29.05 & 0.14 & 0.26 & --- \\
\hline Mg-5\%wt Gd & 5.20 & 67.49 & --- & 26.62 & 0.20 & 0.48 & --- \\
\hline Mg-10\%wt Gd & 8.94 & 66.21 & 0.62 & 22.79 & 0.34 & 0.90 & 0.20 \\
\hline Mg-15\%wt Gd & 9.40 & 66.55 & 0.28 & 23.50 & --- & 0.26 & --- \\
\hline
\end{tabular}




\section{X-ray diffraction}

Observations with the naked eye of the Mg-alloys after 4 hours immersion in 1 wt.\% $\mathrm{NaCl}$ solution at $21.5{ }^{\circ} \mathrm{C}$ showed that their surface was covered with a white compound. The XRD patterns of the $2 \mathrm{wt} . \% \mathrm{Gd}$ alloy are presented in Fig. 7. Similar XRD patterns were obtained for the four studied Mg-alloys but are not shown. They were compared with the JCPDS Card No. 44-1482 and with the JCPDS card No. 35-0821 for identifying $\mathrm{Mg}(\mathrm{OH})_{2}$ and magnesium metal, respectively. The peaks at around $2 \theta=18.5,38.0,58.7$ and 68.8 were assigned to the brucite type $\mathrm{Mg}(\mathrm{OH})_{2}$. The product could be indexed to the hexagonal structure of magnesium hydroxide. In addition, the peaks at around $2 \theta=32.3$, $34.5,36.7,47.9,57.6,63.3,67.6,68.8,70.3,72.8,78.9$ and 81.9 were attributed to $\mathrm{Mg}$ metal. It is well known that the corrosion products of $\mathrm{Mg}$ in $\mathrm{NaCl}$ solutions are mainly $\mathrm{Mg}(\mathrm{OH})_{2}$ and amorphous $\mathrm{MgO}$ phase $[42,45]$.

\section{Discussion}

Alloying is one of the most used methods of enhancing the corrosion resistance of $\mathrm{Mg}$ and its alloys. The immersion of $\mathrm{Mg}$-alloys in $\mathrm{NaCl}$ aqueous solutions involves a corrosion process that is concomitant with $\mathrm{H}_{2}$ evolution and consequently an increase in the $\mathrm{pH}$ of the solution. The results obtained by weight loss determinations, OCP measurements, potentiodynamic scans, and EIS plots were in accordance with the deduction of corrosion process of the $\mathrm{Mg}-10$ wt.\% Gd alloy.

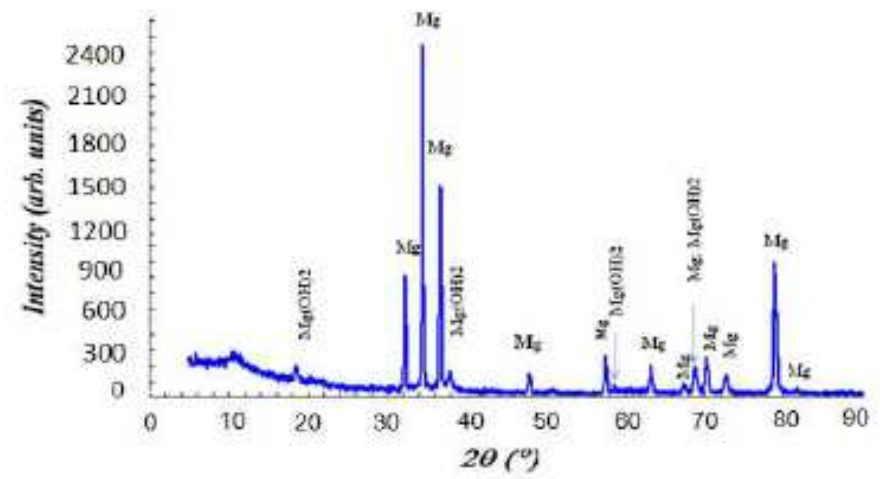

Figure 7. X-ray diffraction patterns of $\mathrm{Mg}-2 \mathrm{wt} . \% \mathrm{Gd}$ alloy after 4hours of immersion in 1 wt. $\% \mathrm{NaCl}$ solution at $21.5^{\circ} \mathrm{C}$.

Corrosion of this last alloy was lower in $1 \mathrm{wt} . \% \mathrm{NaCl}$ alkaline solution because of the lower mass loss, reduced corrosion current $\left(\mathrm{I}_{\text {corr }}\right)$, corrosion potential ( $\left.\mathrm{E}_{\text {corr }}\right)$ shift in the positive direction, and the enlarged capacitive loop that which represented larger charge transfer resistance, Rct. The morphology and composition of the corrosion compounds obtained for the Mg-10 wt.\% Gd alloy seem to be different to those of the other studied alloys. The predominance of the $\beta$-phase in the Mg-10 wt.\% Gd alloy should increase the compactness of the $\mathrm{Mg}(\mathrm{OH})_{2}$ formed on the Mg-alloy surface, which slows down the dissolution of the corrosion product and consequently decreases the corrosion rate of the $\mathrm{Mg}$ alloy [7]. The reason might be that after the addition of $10 \mathrm{wt} \% \mathrm{Gd}$ in the magnesium matrix, the $\beta$-phase particles are easy to precipitate in the magnesium 
matrix during the process of heat treatment processing. Furthermore, the morphology of the film, which is continuous over the exposed surface, plays the role of a corrosion barrier. Additionally, based on the presence of $\mathrm{Na}^{+}$and $\mathrm{Cl}^{-}$ ions in composition of corrosion compounds, as shown by the EDS analysis, in the case of $\mathrm{Mg}-10 \mathrm{wt} . \% \mathrm{Gd}$ alloy, the formed film impedes diffusion of these aggressive ions to the metal interface. In case of weight loss experiments, visual observation of the Mg-10 wt.\% Gd electrode surface during the immersion tests revealed a continuous decrease in the rate of hydrogen gas evolution on its surface with time, compared with the other alloys, suggesting a decrease in the corrosion rate.

\section{Conclusions}

The corrosion behavior of Mg-2 wt.\% Gd, Mg-5 wt.\% Gd, Mg-10 wt.\% Gd, and Mg-15 wt.\% Gd was studied using weight loss, OCP, electrochemical measurements, SEM-EDS, and RXD techniques in 1 wt. $\% \mathrm{NaCl}$ solution. The electrochemical results were consistent with the weight loss measurements. Alloying was observed to play an important role in modulating the corrosion behavior of the Mg-alloys. Thus, introduction of $10 \mathrm{wt} . \% \mathrm{Gd}$ in the $\mathrm{Mg}$ matrix improved the corrosion resistance appreciably in $1 \mathrm{wt} . \% \mathrm{NaCl}$ solution.

\section{Acknowledgements}

This work was supported financially by the CNRST through the competence Pôle PECCA. The authors also would like to thank W. Dietzel and N. Hort and their team at the Institute of Materials Research, Max-Planck-Str. 1, D-21502 Geesthacht, Germany, for providing the $\mathrm{Mg}$ alloys and also $\mathrm{M}$. Es-Souni and S. Habouti at the Institute for Materials \& Surface Technology (IMST) HAW Kiel-University of Applied Sciences, Grenztrasse 3, D-24149 Kiel, Germany, for performing the XRD, SEM and EDS analyses.

\section{References}

1. Blawert C, Morales ED, Dietzel W, et al. Comparison of corrosion properties of squeeze cast and thixocast MgZnRE alloys. Mater Sci Forum. 2005; 488-489: 697-700.

2. Majumdar JD, Galun R, Mordike B, et al. Effect of laser surface melting on Corrosion and water resistance of a commercial magnesium alloy. Mater Sci Eng A. 2003;361:119-129.

3. Song W, Martin HJ, Hicks A, Seely D, Walton CA, Lawrimore II WB, Wang PT, Horstemeyer MF. Corrosion behaviour of extruded AM30 magnesium alloy under salt-spray and immersion environments. Corros Sci. 2014; 78: 353-368.

4. Song G, Atrens A. Corrosion mechanisms of magnesium alloys. Adv Eng Mater. 1999; 1: 11-33.

5. Gray JE, Luan B. Protective coatings on magnesium and its alloys- a critical review. J Alloys Compd. 2002; 336:88-113.

6. Ghali E, Dietzel W, Kainer K. General and localized corrosion of magnesium alloys: acritical review, J 11 Mater Eng Perform. 2004; 1: 7-23. 
7. Hort N, Huanga Y, Fechner D, et al. Magnesium alloys as implant materials - Principles of property design for Mg-RE alloys. Acta Biomater. 2010; 6: 1714-1725.

8. Choi Y, Salmanb S, Kuroda K, et al. Improvement in corrosion characteristics of AZ31 Mg alloy by square pulse anodizing between transpassive and active regions. Corros Sci. 2012;63: 5-11.

9. Hänzi, A.C., Gunde, P., Schinhammer, M., et al. On the biodegradation performance of an Mg-Y-RE alloy with various surface conditions in simulated body fluid. Acta Biomater. 2009; 5: 162-171.

10. Zhao L, Cui C, Wang Q, et al. Growth characteristics and corrosion resistance of micro-arc oxidation coating on pure magnesium for biomedical applications. Corros Sci. 2010; 52: 2228-2234.

11. Srinivasan A, Huanga Y, Mendis CL, et al. Investigations on microstructures, mechanical and corrosion properties of $\mathrm{Mg}-\mathrm{Gd}-\mathrm{Zn}$ alloys. Mater Sci Eng A. 2014; 595: 224-234.

12. Doepke A, Xue D, Yun Y, et al. Corrosion of organosilane coated Mg4Y alloy in sodium chloride evaluated by impedance spectroscopy and $\mathrm{pH}$ change. Electrochem Acta. 2012; 70:165- 170.

13. Zhao X, Shi LL, Xu J. A Comparison of Corrosion Behavior in Saline Environment: Rare Earth Metals (Y, Nd, Gd, Dy) for Alloying of Biodegradable Magnesium Alloys. J Mater Sci Technol. 2013; 29: 781-787.

14. Liu M, Schmutz P, Uggowitzer PJ, et al. The influence of yttrium (Y) on the corrosion of Mg-Y binary alloys. Corros Sci. 2010; 52: 3687-3701.

15. Kubasek J, Vojtech D. Structural and corrosion characterization of biodegradable $\mathrm{Mg}-\mathrm{RE}$ ( $\mathrm{RE}=\mathrm{Gd}, \mathrm{Y}, \mathrm{Nd}$ ) alloys. T Nonferr Metals Soc. 2013; 23: 1215-1225.

16. Peng Q, Wang $\mathrm{J}, \mathrm{Wu} \mathrm{Y}$, et al. The effect of $\mathrm{La}$ or Ce on ageing response and mechanical properties of cast $\mathrm{Mg}-\mathrm{Gd}-\mathrm{Zr}$ alloys. Mater Character. 2008; 59: 435-439.

17. Yang L, Huang Y, Peng Q, et al. Mechanical and corrosion properties of binary Mg-Dy alloys for medical applications. Mater Sci Eng B. 2011; 176: 1827-1834.

18. Yang L, Huang Y, Feyerabend F, et al. Microstructure, mechanical and corrosion properties of $\mathrm{Mg}-\mathrm{Dy}-\mathrm{Gd}-\mathrm{Zr}$ alloys for medical applications. Acta Biomater. 2013; 9: 8499-8508. 12

19. Yang L, Huang Y, Feyerabend F, et al. Influence of ageing treatment on microstructure, mechanical and bio-corrosion properties of $\mathrm{Mg}-\mathrm{Dy}$ alloys. $\mathrm{J}$ Mech Behav Biomed Mater. 2012; 13: 36-44.

20. Yang L, Hort N, Laipple D, et al. Element distribution in the corrosion layer and cytotoxicity of alloy $\mathrm{Mg}-10 \mathrm{Dy}$ during in vitro biodegradation. Acta Biomater. 2013; 9: 8475-8487.

21. Leng Z, Zhang J, Yin T, et al. Influence of biocorrosion on microstructure and mechanical properties of deformed $\mathrm{Mg}-\mathrm{Y}-\mathrm{Er}-\mathrm{Zn}$ biomaterial containing 18R-LPSO phase. J Mech Behav Biomed Mater. 2013; 28: 332339. 
22. Song G. Recent progress in corrosion and protection of magnesium alloys. Adv Eng Mater. 2005; 7: 563-586.

23. Zhao MC, Liu M, Song G, et al. Influence of the b-phase morphology on the corrosion of Mg alloy AZ91. Corros Sci. 2008; 50: 1939-1953.

24. Song G, Atrens A, Wu Z, et al. Corrosion behavior of AZ21, AZ501, and AZ91 in sodium chloride. Corros Sci. 1998; 40: 1769-1791.

25. Schlüter K, Shi Z, Zamponi C, et al. Corrosion performance and mechanical properties of sputter-deposited $\mathrm{MgY}$ and Mg-Gd alloys. Corros Sci. 2014; 78: 43-54.

26. Mueller WD, Nascimento ML, Mele MFL. Critical discussion of the results from different corrosion studies of $\mathrm{Mg}$ and $\mathrm{Mg}$ alloys for biomaterial applications. Acta Biomater. 2010; 6: 1749-1755.

27. Gao L, Zhang C, Zhang M, et al. The corrosion of a novel Mg-11Li-3Al$0.5 \mathrm{RE}$ alloy in alkaline $\mathrm{NaCl}$ solution. J Alloys Compd. 2009; 468: 285289.

28. Laouini E, Douch J, Hamdani M, et al. Cathodic behaviour of $\mathrm{CoFe} 2 \mathrm{O} 4$ spinel electrodes in alkaline medium. J Appl Electrochem. 2011; 41: 731740.

29. Laouini E, Hamdani M, Pereira MIS, et al. Impedance study of spinel Type $\mathrm{Fe}-\mathrm{Co} 3 \mathrm{O} 4$ oxide thin film electrodes in alkaline medium. Int J Electrochem Sci. 2009; 4: 1074-1084.

30. Doepke A, Kuhlmanna J, Guo X, et al. A system for characterizing Mg corrosion in aqueous solutions using electrochemical sensors and impedance spectroscopy. Acta Biomater. 2013; 9: 9211-9219.

31. Ambat R, Aung NN, Zhou W. Studies on the influence of chloride ion and $\mathrm{pH}$ on the corrosion and electrochemical behaviour of AZ91D magnesium alloy. J Appl Electrochem. 2000; 30: 865-874.13

32. Zeng R, Zhang J, Huang W, et al. Review of studies on corrosion of magnesium alloys. Trans Nonferrous Met Soc China. 2006; 16: 763-771.

33. Kartsonakis IA, Balaskas AC, Koumoulos EP, et al. Evaluation of corrosion resistance of magnesium alloy ZK10 coated with hybrid organic-inorganic film including containers. Corros Sci. 2012; 65: 481-493.

34. Pebere N, Riera C, Dabosi F. Investigation of magnesium corrosion in aerated sodium-sulfate solution by electrochemical impedance spectroscopy. Electrochim Acta. 1990; 35: 555-561.

35. Mathieu S, Rapin C, Hazan J, et al. Corrosion behaviour of high pressure die-cast and semi-solid cast AZ91D alloys. Corros Sci. 2002; 44: 27372756.

36. Baril G, Pebere N. The corrosion of pure magnesium in aerated and deareated sodium sulfate solutions, Corros Sci. 2001; 43: 471-484.

37. Feliu S, Samaniego A, Barranco V, et al.A study on the relationships between corrosion properties and chemistry of thermally oxidised surface films formed on polished commercial magnesium alloys AZ31 and AZ6. Appl Surf Sci. 2014; 295: 219-230.

38. Feliu SJ, Samaniego A, Barranco V, et al. The effect of low temperature heat treatment on surface chemistry and corrosion resistance of commercial 
magnesium alloys AZ31 and AZ61 in $0.6 \mathrm{M} \mathrm{NaCl}$ solution. Corros Sci. 2014; 80: 461-472.

39. King AD, Birbilis N, Scully JR. Accurate electrochemical measurement of magnesium corrosion rates, a combined impedance, mass loss and hydrogen collection study. Electrochim Acta. 2014; 121: 394-406.

40. Xin YC, Liu CL, Zhang WJ, et al. Electrochemical behavior A12O3/Al coated surgical AZ91 magnesium alloy in simulated body fluids. J Electrochem Soc. 2008; 155: C178 C182.

41. Fekry AM, Ameer MA. Electrochemistry and Impedance Studies on Titanium and Magnesium Alloys in Ringer's Solution. Int J Electrochem Sci. 2011; 6: 1342-1354.

42. Baril G, Galicia G, Deslouis C, et al. An Impedance Investigation of the Mechanism of Pure Magnesium Corrosion in Sodium Sulfate Solutions. J Electrochem Soc. 2007; 154: C108-C113.

43. Song G, Atrens A, John DS, et al. The corrosion dissolution of magnesium in chloride and sulphate solutions. Corros Sci. 1997; 39: 1981-2004.

44. Pinto R, Ferreira MGS, Carmezim MJ, et al. The corrosion behaviour of rare-earth containing magnesium alloys in borate buffer solution. Electrochim Acta. 2011; 56: 1535-154.

45. Wang L, Zhang BP, Shinohara T. Corrosion behavior of AZ91 magnesium alloy in dilute $\mathrm{NaCl}$ solutions. Mater Design. 2010; 31: 857-863.

46. Wang $\mathrm{N}$, Wang $\mathrm{R}$, Peng $\mathrm{C}$, et al. Corrosion behavior of $\mathrm{Mg}-\mathrm{Al}-\mathrm{Pb}$ and $\mathrm{Mg}-$ Al-Pb-Zn-Mn alloys in 3.5\% NaCl solution. T Nonferr Metals Soc. 2010; 20: 1936-1943. 